\title{
REVENUE SHARING AND COMPETITIVE BALANCE IN PROFESSIONAL TEAM SPORTS
}

Prof. dr. Stefan Késenne

UFSIA, univ. of Antwerp

Prinsstraat, 13

B-2000 Antwerp

Tel. 003232204105

Fax. 003232204799

e-mail.Stefan.kesenne@ufsia.ac.be

Belgium 
ABSTRACT

The aim of this paper is to clarify the apparent confusion in the literature about the impact of a revenue sharing arrangement on the competitive balance in a sports league. A crucial factor in the discussion seems to be the impact of the 'absolute' quality of the teams on the clubs' revenues, beside the impact of the relative quality. The analysis shows that revenue sharing improves the competitive balance under both the profit and the utility maximizing hypothesis. 


\section{REVENUE SHARING AND COMPETITIVE BALANCE IN PROFESSIONAL TEAM SPORTS}

\section{Introduction}

The competitive balance in a sports league, which depends primarily on the distribution of playing talent among teams, is an important element affecting public interest and the financial health of the industry of professional team sports. The well-known Bosman verdict of the European Court of Justice (december 1995) abolished the player reservation system and the payment of tranfer fees for end-of-contract players. The UEFA, the European soccer association, and the national associations had to think of new ways to protect and support the smaller clubs and to guarantee the needed competitive balance in European and national competitions. One of the alternative regulations considered by league administrations, to improve the distribution of playing talent, is a system of revenue sharing among the big clubs and the small clubs. Because smaller clubs were net-sellers of playing talent on the transfer market, the tranfer system has always functioned somehow as a financial redistribution system. In the American major leagues like Baseball (MLB) and Football (NFL) revenue sharing has already become common practice. However, the economic liturature is not very consistent in its approach to the impact of revenue sharing on the competitive balance in a league. In his pioneering contribution Rottenberg (1956) argued that under the profit maximizing assumption revenue sharing among clubs does not affect the distribution of playing talent. Later on, 
this result was formally proven by El Hodiri and Quirk (1971). In a review article for the Journal of Economic Literature, Fort and Quirk (1995) conclude from their analysis that: "gate revenue sharing has no impact on competitive balance in the absence of local TV", meaning that, if clubs receive local television rights that are not shared, the sharing of all other revenue changes the competitive balance. Also Vrooman (1995) agrees that revenue sharing does not affect competitive balance, although he asserts that the sharing of "winning-inelastic" revenue does increase competitive balance.

In the meantime however, Atkinson, Stanley and Tschirhart (1988), using a more general model, showed that revenue sharing does have an impact on the distribution of playing talent. Also Marburger (1997), modelling attendances as an increasing function of the absolute quality of both the home and the visiting team, found that: "the increased sharing of revenues may enhance competitive balance ".

Késenne (1996), starting from a win maximizing model under the breakeven restriction, found that revenue sharing results in a more equal distribution of playing talent, even if absolute quality is left out. Finally, Rascher (1997), aware of the inconsistency of the literature, concluded from his analysis, including absolute quality, that: "El Hodiri and Quirk and Fort and Quirk are correct in their assertion that revenue sharing has no effect on the distribution of talent under individual team profit maximization ". The Rascher paper is interesting because it also turns away from the pure profit maximizing assumption and introduces a utility maximizing model where not only the owner profits are included but also the winning percentage of a team. The inclusion of a separate winning motive in the objective function changes the impact of revenue sharing on the competitive balance. The confusion in the literature is intensified by the differences in approach, the different models and the different methodology used in these papers.

This contribution attempts to clarify these apparent contradictions in the literature. Does or does not revenue sharing affect the competitive balance in a league and under what conditions? In section 2 we start from a profit maximizing model with a fairly general revenue function and try to derive the impact of revenue sharing. Chapter 3 introduces two types of utility maximizing models, where the impact of revenue sharing is compared. Chapter 4 concludes.

\section{Revenue sharing in the profit maximizing scenario}

We specify a model of a professional sports league with $n$ clubs, each playing a home and a road game against every other club. The number of games played by every team in one championship is then 2(n-1). The revenue of club $i$ playing a home game against club $j$ is called $R_{i j}$. If revenues are shared among clubs with share parameter $\mu$, the total season revenue $R_{i}$ of each club i can be written as: 
$R_{i}=\mu \sum_{j \neq i}^{n} R_{i j}+(1-\mu) \sum_{j \neq i}^{n} R_{j i} \quad$ all $i$

Based on the empirical research in the USA and Europe the revenues of a game depend primarily on the home club's catchment area or the size of the market $M_{i}$, being the main determinant of the drawing potential for spectators. The second important determinant is the winning percentage of the home team $W_{i}$, spectators like to see their team win. This winning percentage of a team is an approximation of the relative quality of a team, compared to all other teams in the league. A third important factor is the quality of the visiting team, which can be represented by the winning percentage of that team $W_{j}$. Some recent empirical evidence suggests that not only the relative quality, but also the absolute quality of a ball game significantly affects attendances (see Bruggink and Eaton, 1996). Spectators prefer to watch two high quality teams playing rather than two lousy teams, whatever the closeness of the game or the championship. This absolute quality can be approached in different ways, one way is to take the number of playing talents of both teams, as done by Marburger (1997), not including explicitely the winning percentage of the home team. One might also consider the winning percentage of the visiting team as an quality indicator, which is more appropriate to our model. Indeed, the highest absolute quality of a play can be expected from the two teams with the highest winning percentages. So the following revenue function can be specified:

$R_{i j}=R_{i j}\left(M_{i}, W_{i}, W_{j}\right) \quad$ all $i, j$

where:

$$
\frac{\partial R_{i j}}{\partial M_{i}}>0 \quad \frac{\partial R_{i j}}{\partial W_{j}}>0 \quad \frac{\partial R_{i j}}{\partial W_{i}}>0 \quad \frac{\partial^{2} R_{i j}}{\partial W_{i}^{2}}<0
$$

We also assume that the impact of the winning percentage of a team on its home game attendance is larger than on the away game attendance, an assumption that is also supported by empirical evidence (see Janssens and Késenne, 1987), i.e.:

$$
\frac{\partial R_{i j}}{\partial W_{i}}>\frac{\partial R_{j i}}{\partial W_{i}} \quad \text { and } \quad \frac{\partial R_{j i}}{\partial W_{j}}>\frac{\partial R_{i j}}{\partial W_{j}} \quad \text { all } i, j
$$


Some empirical studies point out that also the uncertainty of outcome has a significant positive effect on attendances and revenues (see Jennett, 1984; Janssens and Késenne, 1987). It is not so much the uncertainty of outcome in an individual game, but rather the closeness of the league championship that affects spectators' interest. This uncertainty of outcome is captured by the negativity of the second-order derivative of the revenue function w.r.t. the winning percentage of the home team.

The winning percentage of a team depends on its playing talent in proportion to the playing talent of the other teams in the league. Since the winning percentages of all teams add up to one, changes in winning percentages are zero-sum across teams. If the total supply of playing talents is constant, also changes in playing talents are zero-sum across teams. In order to simplify the analysis we assume that the winning percentage of a team is an increasing function of the ratio of its playing talent to the total supply of talent in the league, which it put equal to unity. We further assume, following Fort and Quirk (1995) that talent is measured in units such that an additional unit of talent increases the winning percentage by one unit, and that the loss of playing talent, caused by an increase of playing talent by one team, is spread evenly across the opponents. It follows that:

$$
\begin{array}{ll}
\frac{\partial W_{i}}{\partial L_{i}}=1 & \text { all } i \\
\frac{\partial W_{j}}{\partial L_{i}}=\frac{-1}{(n-1)} & \text { all } i, j
\end{array}
$$

On the cost side the only variable cost taken into account is the player cost. In the player market labour is obviously very heterogeneous, each player has a different number of playing talents. If $C$ is the salary level of one playing talent, the total season cost of club $i$ is $C L_{i}+$ a fixed cost. This simplifying assumption leaves many interesting aspects of the player labor market uncovered, but they are not relevant for the purpose of this paper. In accordance with the empirical evidence given by Szymanski and Smith (1997) we assume that, under the free agency conditions after the Bosman verdict in Europe, clubs purchase playing talents in a competitive labour market.

In order to find the equilibrium on the player labor market, the demand for playing talent of each club has to be derived. Under the profit maximizing hypothesis this can be found by equalizing the marginal revenue of playing talent and its salary level $C$, i.e.:

$$
\frac{\partial R_{i}}{\partial L_{i}}=\mu \sum_{j \neq i}^{n} \frac{\partial R_{i j}}{\partial L_{i}}+(1-\mu) \sum_{j \neq i}^{n} \frac{\partial R_{j i}}{\partial L_{i}}=C
$$


Adding the $n$ demands functions and confronting the market demand with the market supply of playing talent yields the market equilibrium with market clearing salary level $C^{*}$ and the corresponding hirings of playing talent by each club $L_{i}{ }^{*}$. A well known result from these models is that, under fairly general conditions and no revenue sharing $(\mu=1)$, the richer club with the larger catchment area will also have a higher number of playing talents, because they can afford to attract and to pay the best players (see: Quirk and Fort, 1992).

This brings us to the central question of this paper: how does a decrease in the share parameter $\mu$ affect the distribution of playing talent? Following Marburger (1997), the answer can be found by investigating the shifts of the clubs'demand curves for playing talent due to a change in the share parameter. These shifts are given by the first derivative of the marginal revenue in (6) with respect to the share parameter $\mu$, taking into account the simplifications in (5), i.e.:

$$
\sum_{j \neq i}^{n}\left[\left(\frac{\partial R_{i j}}{\partial W_{i}}-\frac{\partial R_{j i}}{\partial W_{i}}\right)+\frac{1}{n-1}\left(\frac{\partial R_{j i}}{\partial W_{j}}-\frac{\partial R_{i j}}{\partial W_{j}}\right)\right] \quad \text { all } i
$$

The sign of expression (7) is positive, based on the assumptions made in (4). It follows that the demand for playing talent of each club is coming down if revenues are shared; the incentive to buy extra playing talent is smaller if the marginal revenue of playing talent has to be shared with other clubs in the league. An important implication of this is that the market clearing wage for playing talent decreases and that owners' profits go up.

The more important issue of this paper is the impact of revenue sharing on the distribution of playing talents across teams. It is generally accepted that revenue sharing does not affect the competitive balance in a league if clubs are profit maximizers (see Rottenberg, 1956, Noll, 1974, Quirk and El Hodiri, 1974; Fort and Quirk, 1995; Vrooman, 1995; Rascher, 1997). The downward shifts of the demand curves will leave the distribution of playing talent across clubs unaffected only if the size of these shifts at the market equilibrium point are the same for all clubs. If the downward shifts of demand of the richer clubs are stronger, a more equal distribution of playing talents will emerge. In general, it can not be derived that (7), after substitution of the equilibrium condition, is independent of $i$, indicating that the shifts of the demand curves are different for each club, so that one cannot conclude that revenue sharing has no impact on the talent distribution in a league. A simplified counter example, based on a quadratic revenue function where both the relative and the absolute quality matter, shows that revenue sharing can have an impact on the talent distribution. Let the revenue function be specified as:

$R_{i j}=M_{i} W_{i}-.5 W_{i}^{2}+b_{i} W_{j}$ 
where the size of the market $M_{i}$ is assumed to be larger for the big clubs, and $b_{i}$ captures the positive impact of the quality of the visiting team. We assume that the value of $b_{i}$ only depends on the size of the market of a club, whatever the winning percentage of the team. So the larger is the drawing potential of a franchise, the higher the value of $b_{i}$. The revenue function is quadratic in the winning percentage of the home team because of the decreasing marginal impact of winning on revenue, due to the impact of the uncertainty of outcome. This specification implies that the demand curves for playing talent are linearly decreasing functions with equal slopes for all clubs. However, the level of the demand for playing talent of the big clubs' is higher because of their larger market size $M_{i}$ and the higher value of $b_{i}$. Given this revenue function expression (7) can now be written as:

$$
\frac{n(n-2)}{(n-1)}\left(M_{i}-W_{i}\right)+\frac{n}{(n-1)}[M-W-(n-1) b]
$$

where $M, W$ and $b$ are the average values of $M_{i}, W_{i}$ and $b_{i}$.

In a labor market equilibrium without revenue sharing $(\mu=1)$ it holds for all clubs that:

$\frac{\partial R_{i}}{\partial L_{i}}=(n-1)\left(M_{i}-W_{i}\right)-b_{i}=C^{*}$

where $C^{*}$ is the market clearing cost of a playing talent. Substitution of (10) into (9) yields:

$$
\frac{n(n-2)}{(n-1)^{2}}\left(C^{*}+b_{i}\right)+\frac{n}{(n-1)}[M-W-(n-1) b]
$$

This expression is positive because (7) is positive, and it is different for each club so that the downward shift of the labour demand function, due to revenue sharing, is different for each club. The higher the value of the quality parameter $b_{i}$, the larger will be the downward shift in labour demand. Because $b_{i}$ is larger for the big city clubs, they will reduce their demand for playing talents more than the small town clubs. It follows that the new labor market equilibrium after revenue sharing shows a more equal distribution of playing talent among the big and the small clubs.

In other words, if clubs are profit maximizers and if the larger drawing potential of a franchise also implies a larger impact of the quality factor, a decrease in the home team revenue share leads to a more competitive balance. 
A few remarks should be made here.

1. First of all, if the quality or the winning percentage of the visiting team is not included in the model $\left(b_{i}=0\right)$, revenue sharing has no impact on the distribution of playing talent, because the downward shift of the demand curves of all clubs is the same. This is the case where only the relative quality matters; a conclusion that can be found in Quirk and El Hodiri (1974) and Quirk and Fort (1992).

2. It can be seen from (11) that if the impact of quality on revenue is the same for each club $\left(b_{i}=b\right)$, revenue sharing has no impact on the competitive balance, but this can hardly be a reasonable assumption because a club's revenue depends, among other things, on the ticket price and if ticket prices are different in each club, it follows that also the impact of quality on revenue is different, even if the impact of quality on demand (attendance) is the same. However, if the $b_{i}$ 's are small or the differences between the $b_{i}$ 's are small, it is clear that revenue sharing is rather ineffective in changing the competitive balance in a league. This analysis indicates the importance of investigating empirically the impact of the quality of the game. So our conclusion could be adjusted as follows: if clubs are profit maximizers, revenue sharing will improve the competitive balance in a league if the quality of the teams has a considerable positive and different impact on revenue.

3. Expression (11) shows that, if there are only two clubs in the league $(n=2)$, revenue sharing has no impact on the distribution of playing talent even if the quality parameter $\left(b_{i}\right)$ is different for each club. It follows that the results from a two-club model do not generally apply to a $n$-club model.

4. What happens if a clubs also receive revenues that are not shared, like the local broadcasting rights in the U.S.? From the counter example above, it can be seen that in this case the conclusion of Fort and Quirk (1995) is correct that revenue sharing changes the competitive balance. Let revenue function (8) be extended to:

$$
R_{i j}=M_{i} W_{i}-5 W_{i}^{2}+b_{i} W_{j}+R_{i j}^{*}
$$

where $R_{i j}{ }^{*}$ represents the revenues that are not shared. If the impact of $W_{i}$ on these revenues is assumed to be $r_{i}$, it can be seen that expression (11) becomes:

$$
\frac{n(n-2)}{(n-1)^{2}}\left(C^{*}+b_{i}-(n-1) r_{i}\right)+\frac{n}{(n-1)}(M-W-(n-1) b)
$$

showing that the downward shift of the demand curve also depends on the different impact of winning on local tv-rights: the larger $r_{i}$, the smaller the downward shift of the 
demand curve, ceteris paribus. If $b_{i}=0$, as Fort and Quirk (1995) assume, and $r_{i}$ is larger for the bigger clubs, revenue sharing will yield a more unequal distribution of playing talent. If not, the outcome is theoretically undetermined, because the sign of $\left(b_{i^{-}}(n-1) r_{i}\right)$ is unknown.

5. What happens if clubs are sharing revenues that are winning-inelastic? Vrooman (1995) asserts that the sharing of these revenues does increase competitive balance. From the analysis above we cannot in general confirm this result. Indeed, if another source of revenue is added to expression (2), that does not depend on the winning percentage of the home team, the demand for playing talent can only be affected if these revenues are somehow a function of the playing talent. Only in that case Vrooman is right because the same result applies as in the case of the quality factor $W_{j}$.

\section{Revenue sharing in the utility maximizing scenario.}

In Europe most professional sportclubs are considered to be non-profit organisations, although things are changing quite fast. More and more big soccer clubs, especially in Britain start floating on the market, which might turn profit making necessary. Nevertheless, European economists still think of sportclubs as not merely profit maximizing companies. The objectives of a club are considered to be more complicated and to include, among other things, the maximization of succes or wins, which has been called "utility maximization" by P. Sloane (1971). Késenne (1996) and Rascher (1997) both introduced a different and simplified version of this objective and investigated the impact of revenue sharing. Késenne (1996) shows that, if clubs are only win maximizers under the breakeven condition, revenue sharing improves the distribution of playing talent between big and small clubs in a league. Rascher (1997) starts from an objective function which is a linear combination of profits and wins, indicating that revenue sharing changes the distribution of talent if clubs have a different appeal for winning.

So what do we have to conclude with respect to the impact of revenue sharing on the competitive balance if clubs are utility maximizers?

We first present a slightly adjusted variant of the win maximizing model of Késenne (1996). The only change compared with the original model is that it is no longer assumed that clubs have to break even. Zero profits is only a special case of a model where a given reasonable profit rate is guaranteed. If the capital stock of a club is constant in the short run, a constant profit rate also implies a constant profit level. If $P^{\circ}$ is the given level of season profit, a club will maximize the following Lagrange function:

$W_{i}+g_{i}\left(P_{i}^{\circ}-R_{i}+C L_{i}\right)$ 
where $g_{i}$ is the Lagrange multiplier. If revenues are shared as given by equation (1), the demand equation can be written as:

$$
\mu \sum_{j \neq i}^{n} A R_{i j}+(1-\mu) \sum_{j \neq i}^{n}\left(A R_{j i} \frac{L_{j}}{L_{i}}\right)-\frac{P_{i}^{\circ}}{L_{i}}=C
$$

where $A R$ is the average revenue. Taking again the first-order derivative of the righthand side of (13) with respect to $\mu$ yields:

$$
\sum_{j \neq i}^{n} A R_{i j}-\sum_{j \neq i}^{n}\left(A R_{j i} \frac{L_{j}}{L_{i}}\right)
$$

The sign of (14) indicates the direction of the shift in the demand for playing talent. If (14) is positive, revenue sharing causes a downward shift of the demand curve, if it is negative the demand for talent goes up. It is clear that for big clubs (14) is positive, because the average revenue of a big club is higher than the average revenue of a small club and $L_{i}>L_{j}$ if $i$ is a big club. For the smaller clubs (14) is negative. It follows that big clubs will lower their hirings of playing talent and that small clubs will raise their demand for talent if revenues are shared more evenly. The result is a more equal distribution of playing talent and a more balanced league championship.

It is also important to mention that, compared with the Rascher model below, a high profit rate, a low profit rate or no profit rate at all does not change the conclusion that revenue sharing will improve the competitive balance. But if a big club is interested in making big profits, it will spend less money for paying extra playing talent and contributes in this way to a more equal distribution of playing talent.

If the big clubs lower their demand for playing talent and small clubs increase demand, how does revenue sharing affects the salary level? The answer is that initially the salary level goes up given that the downward shift of the big club's demand will be smaller than the upward shift of the small club's demand, because the demand curve for playing talent is the (net) average revenue curve and big clubs have more playing talents than small clubs. Once the Pareto-optimal (profit maximizing) distribution of playing talent is reached, further revenue sharing will lower the salary level.

We believe that this model offers the most realistic approach for Europe where most sports clubs are non-profit organizations whose main interest is to win as many plays as possible and, if possible, the league championship. Only a small number of big clubs, in particular those floating on the stock exchange, are more businesslike and have to guarantee a certain profit rate in order to satisfy the shareholders. But also these big clubs' final objective is to win the championship and to participate in the European Champions League.

Rascher's model (1997) assumes that clubs are maximizing the following utility function: 
$U_{i}=a_{i} W_{i}+\left(R_{i}-C L_{i}\right) \quad$ with $a_{i}>0$

which is a linear combination of wins and profits; if $a_{i}>1$ more weight is put on wins. If we also introduce the impact of absolute quality, as Rascher (1997) does in his paper, the impact of the share parameter on the demand for playing talent is the same as in expression (7), which indicates that also in Rascher's model revenue sharing causes a reduction in the demand for playing talent by all clubs and therefore a decrease of the salary level. However, contrary to the profit maximizing scenario, the reduction of playing talent is not the same in each club. If clubs have a different appeal for winning, revenue sharing changes the distribution of playing talent, even in the absence of absolute quality. This can again be shown using the simplified counter example. Given revenue function (8), it can be found that expression (11) becomes:

$$
\frac{n(n-2)}{(n-1)^{2}}\left(C^{*}+b_{i}-a_{i}\right)+\frac{n}{(n-1)}[M-W-(n-1) b]
$$

This result points out again that, if there are only two clubs in the league, revenue sharing has no impact on the distribution of playing talent because the first term drops if $n=2$. If $n>2$ the first term indicates that the reaction of each club to a revenue sharing arrangement also depends on the their appeal for winning $a_{i}$. It turns out that a club, that shows a greater interest in profit making, will reduce its demand for playing talent more than a club with a strong appeal for winning. This conclusion is somewhat similar but not exactly the same as Rascher'conclusion, who asserts that: "high $a_{i}$ teams will increase their talent and low $a_{i}$ teams will decrease their talent overall if the share parameter decreases". Rascher also asserts that "a desire to win causes a change in the distribution of talent towards less parity when revenue sharing is increased". However, based on our model, this depends on which clubs value winning most, the big or the small clubs. In Britain, the biggest soccer clubs seem to care more about profits, at least they are relatively more profitable than the smaller clubs (see Deloitte \& Touche, 1997). If that is indeed the case it follows that revenue sharing causes a stronger downward shift in the demand for playing talent of the big clubs, so that also in the Rascher model revenue sharing has a favorable impact on the distribution of playing talent among clubs.

\section{Conclusion}


Given the confusion in the literature about the impact of revenue sharing on the distribution of playing talent in a sports league, this paper shows that, generally, revenue sharing can improve the competitive balance, also if clubs are profit maximizers. The main reason why some models do not come to the same conclusion is that they fail to take into account some indicator of the (absolute) quality of the teams as an important determinant of revenues. If only the winning percentage of the home team matters, revenue sharing does not change the distribution of playing talent in the profit maximizing scenario. If clubs are utility maximizers, revenue sharing improves the competitive balance in any case, also if only the winning percentage of the home team, as an indicator of its relative quality, is included in the revenue function. 


\section{References}

- Atkinson S.E., Stanley L.R., Tschirhart J., (1988), Revenue sharing as an incentive in an agency problem: an example from the National Football League, RAND Journal of Economics, vol. 19, $\mathrm{nr} 1$.

- Brugginck T.H, Eaton J.W., (1996), What Takes me out to the Ball Game? In: Fizel J. e.a. (eds.), (1996), Baseball Economics: Current Research, Greenwood P.G., Westport, Conn.

- Cairns J., Jennett N. and Sloane P. (1986), The Economics of Professional Team Sports: A Survey of Theory and Evidence, Journal of Economic Studies, nr. 13,1

- Deloitte \& Touche, (1997), Annual Review of Football Finance, Manchester

- El-Hodiri M. and Quirk J. (1971), An Economic Model of a Professional Sports League, Journal of Political Economy, 79

- Fort R., Quirk J. (1995), Cross-subsidization, Incentives and outcomes in Professional Team Sports Leagues, Journal of Economic Liturature, XXXIII, pp. 1265-1299

- Janssens P., Késenne S. (1987), Belgian Football Attendances, Tijdschrift voor Economie en Management, jg. XXXII, nr.3

- Jennett N., (1984), Attendances, Uncertainty of Outcome and Policy in the Scottish Football League, Scottish Journal of Political Economy, vol.31, nr.2

- Késenne, S., (1996), League Management in Professional Team Sports with Win Maximizing Clubs, European Journal for Sports Management, vol.2, nr.2

- Marburger D.R., (1997), Gate Revenue Sharing and Luxury Taxes in Professional Sports, Contemporary Economic Policy, vol. XV, april

- Noll R., ed., (1994), Government and the Sports Business, Brookings, Washington

- Quirk J., El Hodiri M., (1974), The Economic Theory of a Professional Sports League, in: Noll, R.G., ed. (1974), Government and the Sport Business, Brookings Institution, Washington DC

- Quirk, J., Fort, R.D., (1992), Pay Dirt, the business of professional team sports, Princeton Univ. Press 
- Rascher D.A., (1997), A Model of a Professional Sports League, in: Hendricks, W., (ed.), (1997), Advances in the Economics of Sport, volume 2, JAI-Press Inc. Greenwich, Conn.

- Rottenberg Simon (1956), The Baseball Players' Labor Market, Journal of Political Economy, 64

- Szymanski S., Smith R., (1997), The English Football Industry: profit, performance and industrial structure, International Journal of Applied Economics, vol.11 nr.1

- Sloane P., (1971), The Economics of Professional Football: The Football club as a Utility Maximizer, Scottish Journal of Political Economy, vol.17, no.2

- Vrooman J., (1995), A General Theory of Professional Sports Leagues, $\underline{\text { Southern }}$ Economic Journal, nr. 61/4 